Research Article

\title{
The Evaluation Method of Rock Mass Stability Based on Natural Frequency
}

\author{
Mowen Xie (D), ${ }^{1}$ Weinan Liu $\left(\mathbb{D},{ }^{1}\right.$ Yan Du $\left(\mathbb{D},{ }^{1}\right.$ Qingbo Li $\mathbb{D}^{2},{ }^{2}$ and Hongfei Wang $\mathbb{D}^{2}$ \\ ${ }^{1}$ School of Civil and Resource Engineering, University of Science and Technology Beijing, Beijing 100083, China \\ ${ }^{2}$ Yellow River Engineering Consulting Co., Ltd. (YREC), Zhengzhou 450003, Henan, China \\ Correspondence should be addressed to Weinan Liu; s20160033@ustb.cn
}

Received 18 November 2020; Revised 10 March 2021; Accepted 7 April 2021; Published 26 April 2021

Academic Editor: Xun Xi

Copyright (c) 2021 Mowen Xie et al. This is an open access article distributed under the Creative Commons Attribution License, which permits unrestricted use, distribution, and reproduction in any medium, provided the original work is properly cited.

The limit equilibrium method's analysis index cannot be measured by on-site monitoring equipment and cannot be used for monitoring and early warning of rock instability. The existing rock stability evaluation methods based on vibration information cannot evaluate the stability of rocks quantitatively. In this paper, the slope's constraints on the rock were simplified to springs and a three-dimensional analysis model of rock vibration was established. The equation for calculating the natural frequency of rock that includes the spring stiffness as an indicator was derived. The rock stability calculation function containing the index of natural frequency was brought into the traditional rock stability coefficient calculation equation, and a new rock stability analysis method based on natural frequency was established. The experiment proved the measurability of the index of the natural frequency of rock and the method's effectiveness for the stability analysis of the rock based on natural frequency.

\section{Introduction}

Rock collapse is a common natural disaster [1], and the accurate analysis of rock stability is an essential and necessary work to warn the damage of dangerous rock and reduce the loss of collapse disaster $[2,3]$. The limit equilibrium method is a standard method used in analyzing the stability of rock which uses the principle of static equilibrium to calculate the stability coefficients of rock by analyzing the force states of the rock under various damage modes $[4,5]$. Strength parameters such as cohesion intercept $(c)$ and angle of shearing resistance $(\varphi)$ of the rock or its structural surfaces are important parameters for the analysis of the limit equilibrium method, but these parameters cannot be directly monitored by in situ equipment $[6,7]$.

The universal monitoring indicators for slope monitoring and early warning are two types of surface deformation and vibration information. However, unlike the deformation rate of landslide hazards with a slowly increasing phase, rock collapse has a strong suddenness. When monitoring the stability of rocks using external deformation indicators, it is possible to determine whether the rocks are falling, but it is impossible to give an early warning of rock failure [8]. Because of the invalid external deformation indicators of rock collapse warning, some scholars have started to study the relationship between rock vibration information and its stability.

Spillmann et al. [9] analyzed the stability of rock slope in the Swiss Alps and used the microseismic technique. Xu et al. [10] found the damaged rocks by analyzing the spatial and temporal distribution pattern of microseismic activity in the slope. Salvoni and Dight [11] and Feng et al. [12] monitored rocks' failure on unstable slopes by microseismic networks. Mercerat $[13,14]$ et al. compared the vibration response of unstable rocks and slopes under ambient vibration and found a significant amplification effect of a rock's vibration on the verge of failure. These studies show that rocks' vibration information can reflect the changes in their stability, but the method for quantitative calculation of rock stability has not been given.

To solve this problem, Ma et al. $[15,16]$ and Xie et al. $[17,18]$ proposed some simple mechanical models of rocks and investigated the quantitative relationship between the natural frequency of rocks and their stability. In their study, 
the rock was simplified as a rigid sphere, and the connection between the rock and the slope was simplified as a spring. As the connection area between the slope and the unstable rock decreases, the spring's stiffness gradually decreases and the rock's stability also decreases. The quantitative relationship between the rock's stability and its natural frequency was established by analyzing the spring stiffness [19]. Although the quantitative relationship between the natural frequency of the rock and its stability was given, the above study also has the following problems: (1) treating the rock as a rigid ball ignored the influence of the shape of the rock on its natural frequency; (2) the model can only be used to analyze the natural frequency of the rock in one direction; and (3) the calculation method of the spring stiffness of the connection between the rock and the slope has a large error $[20,21]$.

This paper proposes a new model for rock vibration analysis to remedy the above calculation model's deficiency. The model considers the form of rock vibration in threedimensional space, and the constraints of the slope on the rock were simplified to multiple springs. By establishing the equilibrium equations of motion for the longitudinal, torsional, and transverse swinging vibrations of the rock and connecting them with the rock's boundary conditions, i.e., the springs' stiffness, the equations for solving the formation functions and vibration frequencies of the rock were established. The rock stability coefficients can be calculated using the simultaneous rock natural frequency calculation equation and the rock mechanical equilibrium equation. To analyze the validity of the theoretical calculation results, indoor experiments on the measurability of the rock's natural frequency were conducted. The experimental results proved the validity of the theory.

\section{Proposal of the Method}

2.1. Limit Equilibrium Analysis of Rock Stability. In the analysis of rocks using the limit equilibrium method, a rock's stability is expressed as the ratio of its resistance to the driving force. The rock's driving force is the action of external load such as gravity, and the resistance of the rock is the restraining force of the slope to the rock. For a rock formed by the cutting of a single joint plane, it can be considered that the restraining force is directly related to the area of the joint plane. The cause of the rock's instability and movement can be considered as the decrease in the joint plane area or the weakening of the joint plane's bond strength, leading to the deficiency of the slope's restraining force $[22,23]$.

A typical slope is shown in Figure 1, and the joint plane cuts a rock of weight $W$ out of the slope of unit thickness. The length of the connection between this rock and the slope is $l_{1}$, and the length of separation is $l_{2}$. For this rock, the stability factor $F_{s}$ is shown as follows:

$$
F_{s}=\frac{\tau_{1} l_{1}+\tau_{2} l_{2}}{W \sin \alpha}
$$

where $\tau_{1}$ is the maximum shear stress of the rock connection region, $\tau_{2}$ is the maximum shear stress of the rock separation region, and $\alpha$ is the inclination angle of the joint plane. The value of $\tau_{2}$ is equal to 0 when there is no filling material in the fracture.

Equation (1) indicates that the stability coefficient $F_{s}$ of the rock will decrease as the connection length decreases. Usually, we consider that the rock will become unstable if $F_{s} \leq 1$ [24].

Because the rock material's stiffness is large, the rock's deformation in the decline of the connection length is minimal. It is difficult for the monitoring equipment to monitor the rock's small deformation, so the rock's stability cannot be judged by monitoring the deformation indexes such as displacement. With the decline of the rock and slope's connection length, the slope's restraint on the rock is weakened. As the constraint decreases, the dynamic indexes such as the rock's natural frequency will be changed. If we can give the mathematical expression of the rock's natural frequency and the connection length $l_{1}$ of the slope, we can derive the formula between the nature frequency $f$ of the rock and its stability coefficient $F_{s}$ by eliminating the parameter $l_{1}$ based on equation (1).

\subsection{Calculation of Rock Stability Based on the Natural} Frequency. The model proposed by $\mathrm{Ma}$ et al. [15] and Xie et al. $[25,26]$ for calculating the natural frequency of the rock is shown in Figure 2(a). This model simplifies the rock as a single-degree-of-freedom block and the rock-slope connection as a tension-compression spring $K_{0}$. The calculation formula for the natural frequency $w_{0}$ of the rock is as follows:

$$
w_{0}=\sqrt{\frac{k_{0}}{M}},
$$

where $k_{0}$ is the stiffness of the tension-compression spring $K_{0}$.

Equation (2) gives the formula for calculating the natural frequency of the rock when it is free to vibrate in the vertical joint plane's direction. However, there is not only one way of vibration of the rock. Along with the vertical vibration, the rock also performs swaying or rotational vibration. To analyze the rock's natural frequencies for multiple modes of vibration, it is necessary to create multiple springs to denote the slope restraints on the rock's translation and rotation in three-dimensional space.

As shown in Figure 2(b), the longitudinal vibration of rock along the $Z$-axis, torsional vibration around the $Z$-axis, swinging vibration in the $X Z$-plane, and swinging vibration in the $Y Z$-plane were analyzed at the same time. It is necessary to establish springs $K_{1}, K_{2}, K_{3}$, and $K_{4}$ to represent the boundary conditions of the above four vibrations of the rock, and the stiffnesses of these four springs can be expressed as $k_{1}, k_{2}, k_{3}$, and $k_{4}$. Combining the rock's motion equations and its boundary conditions, the rock vibration function and natural frequency expressions can be calculated.

For the rock shown in Figure 2(b) with length $L$, width $B$, and height $H$, the coordinate system is established with the center of the lower bottom surface of the rock as the origin, and the vibration function of the rock vibrating freely along 


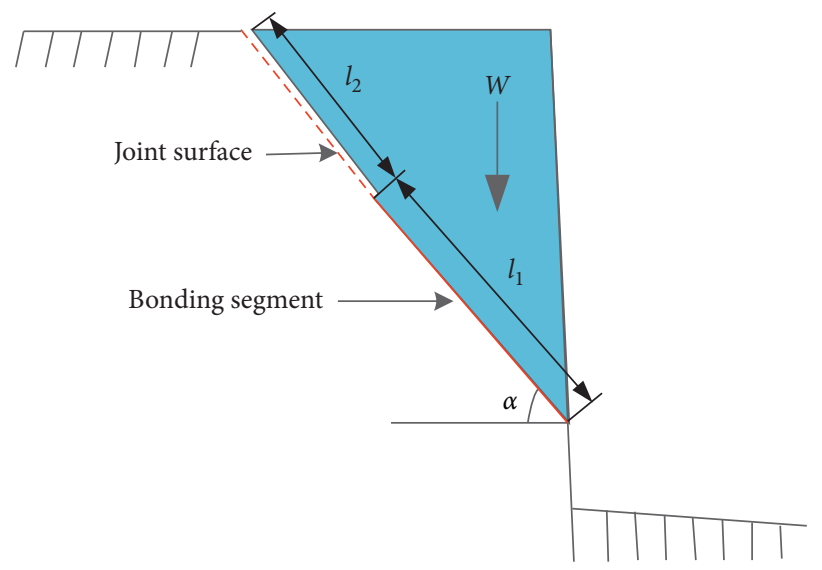

Figure 1: Calculation model of jointed rock.

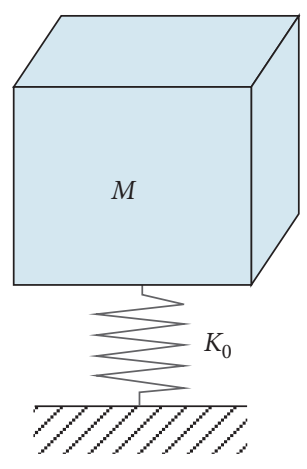

(a)

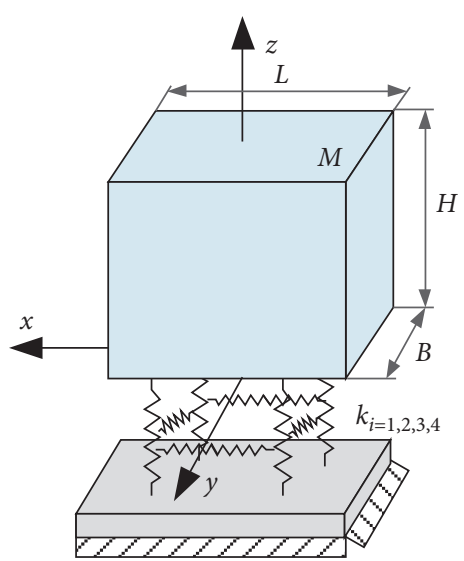

(b)

Figure 2: Simplified model for rock vibration.

the $Z$-axis in the longitudinal direction can be written as follows [27]:

$$
u(z)=B_{1} \cos \left(\frac{w_{1} z}{c_{1}}\right)+B_{2} \sin \left(\frac{w_{1} z}{c_{1}}\right),
$$

where $u$ is the displacement of the rock in the $z$-direction, $B_{1}$ and $B_{2}$ are unknown quantities representing the vibration function of the rock, $w_{1}$ is the frequency of the longitudinal vibration of the rock, and $c_{1}$ is the propagation velocity of the elastic wave along the $Z$-axis. The $c_{1}$ can be calculated by the following equation:

$$
c_{1}=\sqrt{\frac{E}{\rho}},
$$

where $E$ is Young's modulus of the rock and $\rho$ is the density of the rock.

For the rock shown in Figure 2(b), which is free at the top and connected to the slope foundation at the bottom, the boundary conditions can be written as follows:

$$
\left\{\begin{array}{l}
z=0, \quad \operatorname{EBL} \frac{d u}{d z}=k_{1} u, \\
z=0, \quad \frac{d u}{d z}=0 .
\end{array}\right.
$$

Combining equation (5) with equation (3), the formula for calculating the intrinsic frequency of longitudinal vibration of rock can be derived as follows:

$$
k_{1} \cos \left(\frac{w_{1} H}{c_{1}}\right)-\operatorname{EBL}\left(\frac{w_{1}}{c_{1}}\right) \sin \left(\frac{w_{1} H}{c_{1}}\right)=0 .
$$

The longitudinal natural frequency $w_{1}$ of rock can be obtained by introducing the parameters such as size, density, Young's modulus, and Poisson's ratio of rock into equation (6). The satisfying condition (6) has multiple values of $w_{1}$, which represent the frequencies of longitudinal vibration of the rock at different orders.

The calculation methods of the rock's frequencies for torsional vibration around the $Z$-axis swinging vibration in the $X Z$-plane and swinging vibration in the $Y Z$-plane are similar to those of rock torsional vibration around the $X$ - 
axis. Because the calculation process of rock vibration is involved, it may not derive the analytical solution of rock's natural frequency, but the numerical solution of rock's natural frequency can be calculated by taking the parameters such as size and mass of rock.

For the rock shown in Figure 2(b), the constraint stiffness $k_{1}$ of $Z$-direction vibration of slope rock is as follows $[28,29]$ :

$$
k_{1}=\frac{4 G}{1-v} 0.55 \sqrt{B l_{1}}
$$

where $G$ is the shear modulus of the rock and $v$ is Poisson's ratio of the rock.

The formula between the rock connection length $l_{1}$ and its intrinsic frequency $w_{1}$ can be derived from equations (7) and (6). And the stability of the rock can be calculated by bringing $l_{1}$ into equation (1) and assuming that the calculation formula of rock's connection length based on natural frequency is $l_{1}=f(w)$. For the rock in Figure 1 , the maximum shear stress $\tau_{1}$ in the rock's connection area can be calculated by the following equation:

$$
\tau_{1}=c_{1}+\frac{W \cos \alpha}{l_{1}} \tan \varphi_{1},
$$

where $c_{1}$ is the cohesion of the rock and $\varphi_{1}$ is the angle of shearing resistance of the rock.

A new expression of rock stability coefficient can be obtained by incorporating equation (8) into equation (1):

$$
F_{s}=\frac{c_{1} f(w)}{W \sin \alpha}+\cot \alpha \tan \varphi_{1} .
$$

Equation (9) is the formula for calculating the stability coefficient of rock based on the indicator of natural frequency, which replaces the connection length $l_{1}$ of rock with the function of rock's natural frequency $f(w)$. Therefore, the stability of rock can be determined by the indicator of rock's natural frequency after the strength parameters and mass of rock are determined. The rock's strength parameters and mass usually do not change, and the damage caused by the external environment to the rock is mainly in its connection zone with the slope. Using on-site monitoring equipment to measure the change of rock's natural frequency in real-time, we can judge the state of the rock's connection area and realize the dynamic monitoring of rock's stability.

However, the expression $f(w)$ as a function of the rock's natural frequency in equation (9) cannot be given directly. When calculating the rock's connection length $l_{1}$ from its natural frequency, it is necessary to give the numerical solution of $l_{1}$ after bringing in the physical and mechanical parameters of the rock. The material of the rock is defined in Figure 2(b) as one kind of sandstone [30]. When $L=3 \mathrm{~m}$, $B=2 \mathrm{~m}$, and $H=5 \mathrm{~m}$, the variation process line of natural frequency $w$ of the four vibrations of the rock with the decrease in the length $l_{1}$ of the connection is shown in Figure 3. In the figure, FLV is used to represent the longitudinal vibration of rock along the $Z$-axis, FToV is used to represent the torsional vibration of rock around the $Z$-axis, FTrV1 is used to represent the swinging vibration rate of rock in the $X Z$-plane, and FTrV2 is used to represent the swinging vibration of rock in the $Y Z$-plane.

It can be seen from Figure 4 that the natural frequency of the rock decreases with the decline of the connection length. In other words, the natural frequency of the rock decreases as the stability of the rock declines. The results of this theoretical calculation remain consistent with the previous analysis.

\section{Experiments}

In order to analyze the validity of the theoretical model, a simple indoor experiment was carried out. The rock is granite with the length, width, and height of $25 \mathrm{~cm}$, and a rubber pad of thickness $D=3 \mathrm{~cm}$ is laid under the granite with the same area as the cross-section of the rock. To simulate the reducing of rock's connection area, the rubber pad was cut with a knife to reduce its connection length $l_{1}$. As shown in Figure 5, two triaxial accelerometer sensors were glued to the rock's top and side.

The rubber pad was cut $1 \mathrm{~cm}$ at a time, starting from the right side of the model, and then the rock was vibrated by striking the ground or the rock with a small hammer. These two acceleration sensors measured the vibration acceleration of the rock. During each experiment, the vibration acceleration of the rock was recorded for more than 10 seconds. After the vibration acceleration's time-domain curve was recorded, it was converted into a frequency-domain signal using the fast Fourier transform. The time-domain and frequency-domain curves of rock vibration recorded by the sensors when the rubber pad's area was the same as the rock's cross-sectional area are shown in Figure 6.

The rubber pad's length was decreased from $25 \mathrm{~cm}$ to $18 \mathrm{~cm}$ in the experiment, and the data of rock vibration were collected 8 times. The measurement results of the rock's vibration frequencies under various vibration modes during the length drop of the rubber pad are shown in Table 1.

\section{Discussion}

Based on the data in Table 1, the vibration frequencies of rock under different vibration modes are plotted against the rubber pads' length, as shown in Figure 7. From Figure 7, it can be seen that the torsional vibration frequencies of rock bodies located on rubber pads are significantly more than the frequencies of longitudinal vibration and side-swing vibration, and this difference can be maintained in the process of decreasing the length of rubber pads. The change of the frequency of side-swinging vibration of the rock in $X Z$ - and $Y Z$-plane has its apparent characteristics. When the length of the rubber pad $l=25 \mathrm{~cm}$, the swing natural frequency of rock in the $X Z$-plane is equal to that in the $Y Z$-plane. However, as the length of the rubber pad $l$ decreases, both of them show different degrees of decrease, and the decrease in the swinging natural frequency of the rock in the $Y Z$ plane is more pronounced.

It is also necessary to determine the relationship equation between the rock's natural frequency and its connection length to analyze its stability by vibration data. In 


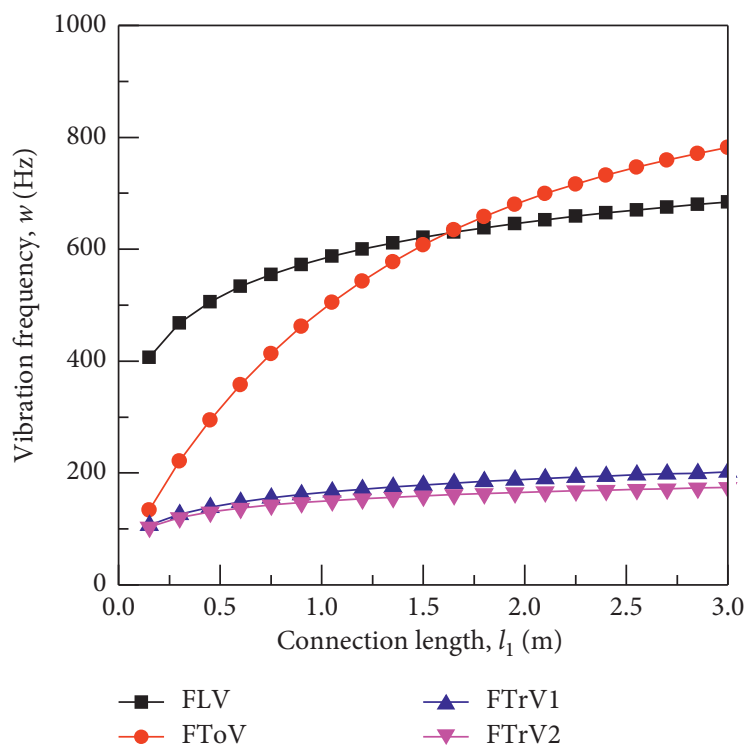

FIGURE 3: Variation of the natural frequency of the rocks.

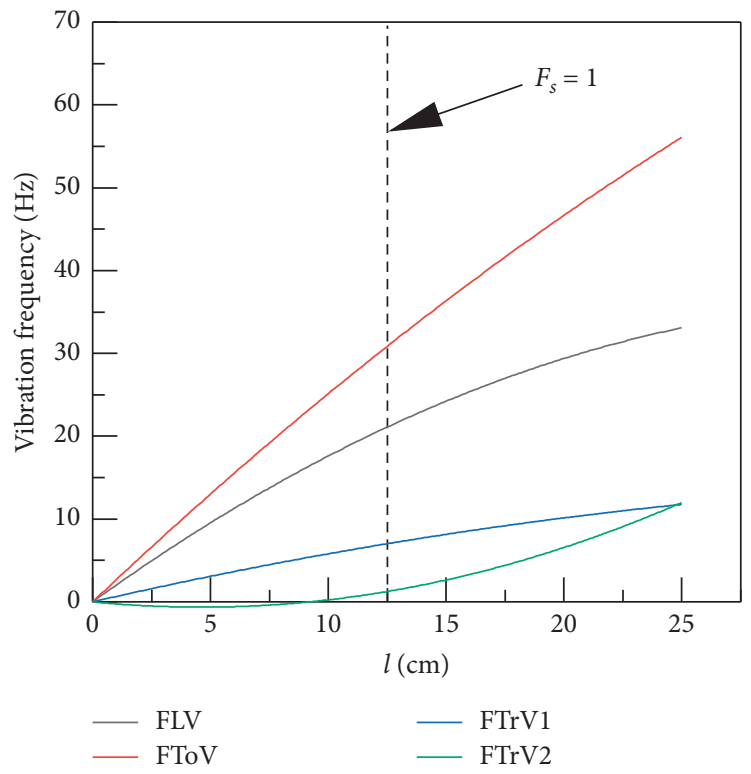

FIGURE 4: Calculation of natural frequency thresholds for rock instability.

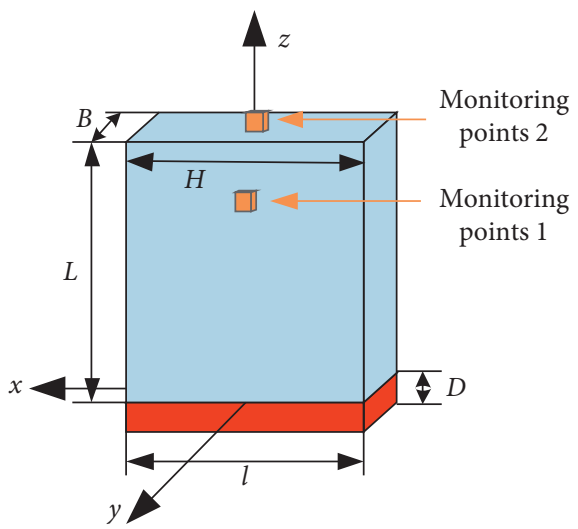

Figure 5: Schematic diagram of the experimental model. 


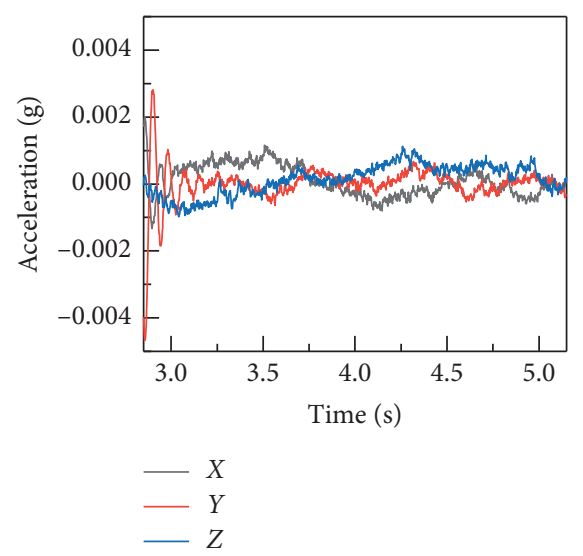

(a)

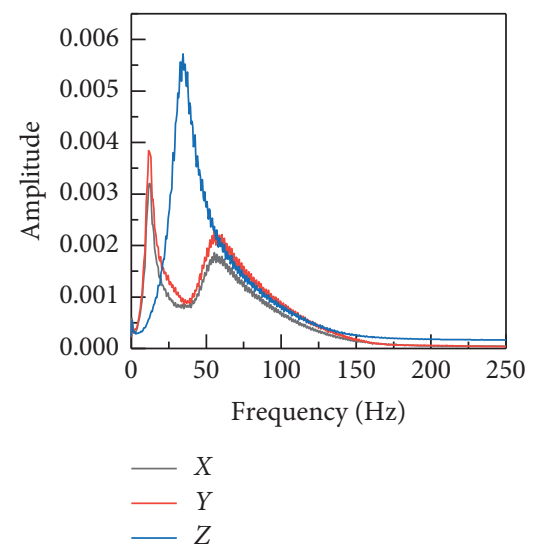

(b)

Figure 6: Monitoring data of measurement point one: (a) time-domain signals of vibration; (b) frequency-domain signal of vibration.

TABLE 1: Rock natural frequency and measurement conditions.

\begin{tabular}{lccccc}
\hline Number & FLV $(\mathrm{Hz})$ & FToV $(\mathrm{Hz})$ & FTrV1 $(\mathrm{Hz})$ & FTrV2 $(\mathrm{Hz})$ & 12.0 \\
\hline 1 & 34.5 & 55.5 & 12.0 & 10.5 & 10.0 \\
2 & 32.0 & 54.5 & 11.5 & 11.0 & 25 \\
3 & 31.0 & 53.5 & 10.5 & 7.5 & 23 \\
4 & 30.0 & 50.0 & 10.5 & 6.5 & 22 \\
5 & 30.0 & 48.5 & 10.0 & 6.0 & 21 \\
6 & 29.5 & 46.5 & 10.0 & 4.5 & 19 \\
7 & 29.0 & 45.5 & 9.5 & 18 \\
8 & 28.0 & 42.0 & & & 20 \\
\hline
\end{tabular}

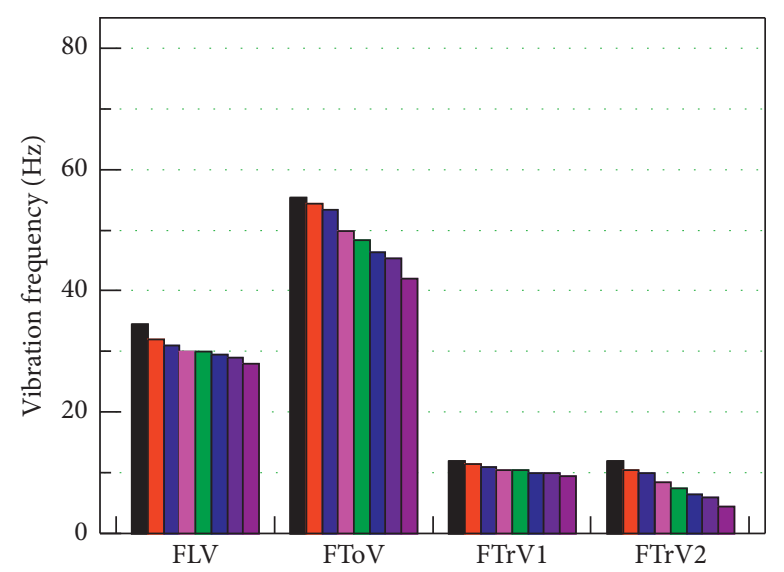

$l(\mathrm{~cm})$

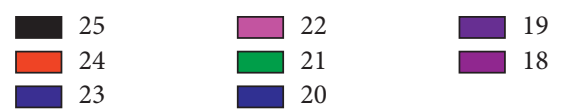

FIgURE 7: Natural frequency of rock under different vibration methods.

the experiments, the rubber mat and the rock's physical and mechanical parameters are unknown quantities, and the experimental data are analyzed using function fitting to determine the equation between the natural frequency $w$ and the connection length $l$. The power function curve's results fitting between the rock's natural frequency and its connection length for the four vibration modes are shown in Figure 8 . 


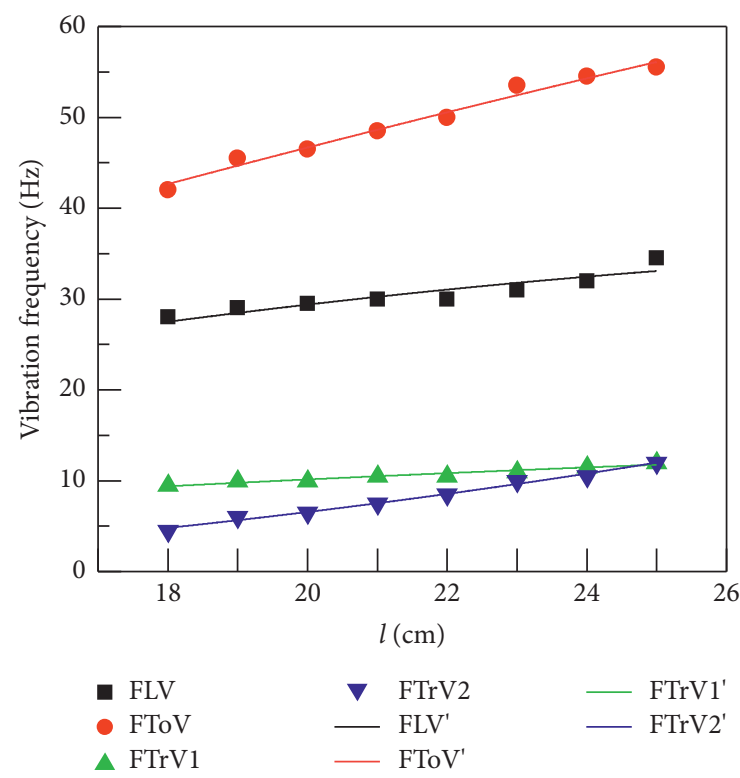

Figure 8: Rock natural frequency curve fitting.

The four calculation equations for the rock connection length $l$ are as follows:

$$
\left\{\begin{array}{l}
w_{\mathrm{FLV}}=-2.053 l-0.029 l^{2}, \\
w_{\mathrm{FToV}}=2.693 l-0.018 l^{2}, \\
w_{\mathrm{FTrV} 1}=0.653 l-0.007 l^{2}, \\
w_{\mathrm{FTrV} 2}=-0.280 l+0.030 l^{2},
\end{array}\right.
$$

where $w_{\mathrm{FLV}}, w_{\mathrm{FToV}}, w_{\mathrm{FTrV} 1}$, and $w_{\mathrm{FTrV} 2}$ represent the rock's vibration frequencies under the four vibration modes of FLV, FToV, FTrV1, and FTrV2. They did not have adhesive force between the rock and the rubber pad in this experiment. Therefore, we can assume that the rock will be unstable when the center of gravity is losing support. The condition of the instability of the rock is $l=12.5 \mathrm{~cm}$. The threshold value of the rock's natural frequency before its instability can be calculated by bringing the criterion of the instability of the rock into equation (2), as shown in Figure 4. The natural frequency thresholds of the rock instability in the experiment are $w_{\mathrm{FLV}}=21.10 \mathrm{~Hz}, w_{\mathrm{FToV}}=30.85 \mathrm{~Hz}, \quad w_{\mathrm{FTrV} 1}=7.02 \mathrm{~Hz}$, and $w_{\mathrm{FTrV} 2}=1.25 \mathrm{~Hz}$.

The experiment shows that the natural frequency of rock can reflect the change of rock stability, and the sensitivity of the natural frequency of rock to the change of connection length is not the same in different vibration modes. Figures 3 and 7 both indicate that the frequency of torsional vibration of rock around the $Z$-axis is the largest when the connection area of rock and slope is complete. However, as the connection length decreases, the frequency of torsional vibration of the rock around the $Z$-axis is the most variable in Figure 3, and the rock swaying vibration in the $Y Z$ plane is the most variable in Figure 7 . The parameters of the sandstone chosen for the calculation of the rock in Figure 3 and the parameters of the experimental material in Figure 7 are different, so we can make a conjecture that the sensitivity of the frequency variation of the different vibration modes of the rock is related to the physical and mechanical parameters of the rock. The proof of this conjecture needs to be further investigated in the subsequent work.

\section{Conclusion}

The limit equilibrium method is a common method for rock stability analysis, but the calculated parameters in this method, such as bond and friction angle, cannot be measured by on-site monitoring equipment. It is necessary to determine the stability analysis methods with monitorable indicators to warn the rocks' failure. The method of rock stability analysis based on vibration information has been proposed, but it cannot accomplish the quantitative analysis of rock stability.

The stability of the rock is controlled by its joint plane. In this paper, the rock's restraint from the slope was simplified as springs, and the springs' stiffness was related to the rock and slope's connection length. Through the rock's vibration function, the method of calculating the natural frequency of the rock containing the variable of spring stiffness is determined. Finally, the calculating formula of the connection length based on the rock's natural frequency index is confirmed. The formula was brought into the rock's limit equilibrium equation, and a model for judging the stability of the rock based on the natural frequency was established.

The article analyzed the change process of rock's natural frequency with its connection length through theoretical calculation and experiment. The result proved the feasibility of rock stability evaluation based on the natural frequency index. However, there are different vibration forms of rocks, and when using the natural frequency index to analyze the stability of rocks, selecting the most sensitive one from the vibration frequencies of multiple vibration modes of rocks is still undetermined, and further research on this is needed.

\section{Data Availability}

The data used to support the findings of this study are included in the supplementary information files.

\section{Conflicts of Interest}

The authors declare that they have no conflicts of interest regarding the publication of this paper.

\section{Acknowledgments}

This project was supported by the National Key Research and Development Program of China (grant no. 2019YFC1509602)

\section{Supplementary Materials}

Frequency Curve Data of Rock Vibration in the Experiment. The vibration frequency data of the rock block are measured and calculated by the vibration sensors installed on the rock block. The first row of data 1 represents sensor 1,2 
represents sensor 2 , and $x, y$, and $z$ indicate the direction of rock vibration. A total of eight experiments were performed on the same block, and a total of eight sets of frequency data were generated. The rubber mat was not cut in the first set of experiments (VibrationMeterMonitoringData-1), and the cut length of the rubber mat was $7 \mathrm{~cm}$ in the eighth set of experiments (VibrationMeterMonitoringData-8). If you have questions about the data, you can contact LIU: grealwn@126.com. (Supplementary Materials)

\section{References}

[1] K. Zhu, P. Xu, C. Cao, L. Zheng, Y. Liu, and X. Dong, "Preliminary identification of geological hazards from songpinggou to feihong in mao county along the minjiang river using SBAS-InSAR technique integrated multiple spatial analysis methods," Sustainability, vol. 13, no. 3, p. 1017, 2021.

[2] R. Jimenez-Rodriguez, N. Sitar, and J. Chacón, "System reliability approach to rock slope stability," International Journal of Rock Mechanics and Mining Sciences, vol. 43, no. 6, pp. 847-859, 2006.

[3] Y. Pan, G. Wu, Z. Zhao, and L. He, "Analysis of rock slope stability under rainfall conditions considering the waterinduced weakening of rock," Computers and Geotechnics, vol. 128, Article ID 103806, 2020.

[4] A. Johari and S. Mousavi, "An analytical probabilistic analysis of slopes based on limit equilibrium methods," Bulletin of Engineering Geology and the Environment, vol. 78, no. 6, pp. 4333-4347, 2019.

[5] S. Y. Liu, L. T. Shao, and H. J. Li, "Slope stability analysis using the limit equilibrium method and two finite element methods," Computers and Geotechnics, vol. 63, pp. 291-298, 2015.

[6] B.-G. Chae, H.-J. Park, F. Catani, A. Simoni, and M. Berti, "Landslide prediction, monitoring and early warning: a concise review of state-of-the-art," Geosciences Journal, vol. 21, no. 6, pp. 1033-1070, 2017.

[7] B. Thiebes, R. Bell, T. Glade, S. Jäger, M. Anderson, and L. Holcombe, "A WebGIS decision-support system for slope stability based on limit-equilibrium modelling," Engineering Geology, vol. 158, pp. 109-118, 2013.

[8] Q. A. Gian, D.-T. Tran, D. C. Nguyen, V. H. Nhu, and D. Tien Bui, "Design and implementation of site-specific rainfallinduced landslide early warning and monitoring system: a case study at Nam Dan landslide (Vietnam)," Geomatics, Natural Hazards and Risk, vol. 8, no. 2, pp. 1978-1996, 2017.

[9] T. Spillmann, H. Maurer, A. G. Green, B. Heincke, H. Willenberg, and S. Husen, "Microseismic investigation of an unstable mountain slope in the Swiss Alps," Journal of Geophysical Research, vol. 112, 2007.

[10] N. W. Xu, F. Dai, Z. Z. Liang, Z. Zhou, C. Sha, and C. A. Tang, "The dynamic evaluation of rock slope stability considering the effects of microseismic damage," Rock Mechanics and Rock Engineering, vol. 47, no. 2, pp. 621-642, 2014.

[11] M. Salvoni and P. M. Dight, "Rock damage assessment in a large unstable slope from microseismic monitoring-MMG Century mine (Queensland, Australia) case study," Engineering Geology, vol. 210, pp. 45-56, 2016.

[12] L. Feng, V. Pazzi, E. Intrieri, T. Gracchi, and G. Gigli, "Joint detection and classification of rockfalls in a microseismic monitoring network," Geophysical Journal International, vol. 222, no. 3, pp. 2108-2120, 2020.
[13] U. Kleinbrod, J. Burjánek, and D. Fäh, "Ambient vibration classification of unstable rock slopes: a systematic approach," Engineering Geology, vol. 249, pp. 198-217, 2019.

[14] J. Burjánek, V. Gischig, J. R. Moore, and D. Fäh, “Ambient vibration characterization and monitoring of a rock slope close to collapse," Geophysical Journal International, vol. 212, no. 1, pp. 297-310, 2018.

[15] G. Ma, K. Sawada, and H. Saitoh, "Study on evaluating rock block stability by using a remotely positioned laser Doppler vibrometer," International Journal of Geomate, vol. 2, pp. 247-252, 2012.

[16] G.-C. Ma, K. Sawada, A. Yashima, and H. Saito, "Experimental study of the applicability of the remotely positioned laser Doppler vibrometer to rock-block stability assessment," Rock Mechanics and Rock Engineering, vol. 48, no. 2, pp. 787-802, 2015.

[17] Z. He, M. Xie, Z. Huang et al., "Experimental hazardous rock block stability assessment based on vibration feature parameters," Advances in Civil Engineering, vol. 2020, Article ID 8837459, 11 pages, 2020.

[18] Y. Du, Y. Lu, M. Xie, and J. Jia, "A new attempt for early warning of unstable rocks based on vibration parameters," Bulletin of Engineering Geology and the Environment, vol. 79, pp. 1-6, 2020.

[19] B. Jia, Z. Wu, and Y. Du, "Real-time stability assessment of unstable rocks based on fundamental natural frequency," International Journal of Rock Mechanics and Mining Sciences, vol. 124, Article ID 104134, 2019.

[20] K. Kim, S. Kim, K. Sok, C. Pak, and K. Han, "A modeling method for vibration analysis of cracked beam with arbitrary boundary condition," Journal of Ocean Engineering and Science, vol. 3, no. 4, pp. 367-381, 2018.

[21] H.-I. Yoon, I.-S. Son, and S.-J. Ahn, "Free vibration analysis of Euler-Bernoulli beam with double cracks," Journal of $\mathrm{Me}$ chanical Science and Technology, vol. 21, no. 3, pp. 476-485, 2007.

[22] X. Xi, Z. Yin, S. Yang, and C.-Q. Li, "Using artificial neural network to predict the fracture properties of the interfacial transition zone of concrete at the meso-scale," Engineering Fracture Mechanics, vol. 242, Article ID 107488, 2021.

[23] X. Xun, W. Xu, G. Qifeng, and C. Meifeng, "Experimental investigation and numerical simulation on the crack initiation and propagation of rock with pre-existing cracks," Ieee Access, vol. 8, pp. 129636-129644, 2020.

[24] Y. Chen and H. Lin, "Consistency analysis of Hoek-Brown and equivalent Mohr-coulomb parameters in calculating slope safety factor," Bulletin of Engineering Geology and the Environment, vol. 78, no. 6, pp. 4349-4361, 2019.

[25] Y. Jia, M. Xie, S. Chang, and F. Lu, "A model for evaluation of stability of sliding- and falling-type dangerous rock blocks based on natural vibration frequency," Rock and Soil Mechanics, vol. 38, pp. 2149-2156, 2017.

[26] Y. Du, M. Xie, F. Lu, Z. Wang, G. Wang, and Q. Liu, "New method for dynamic analysis of rock slope stability based on modal parameters," Chinese Journal of Geotechnical Engineering, vol. 37, pp. 1334-1339, 2015.

[27] Q. S. Li, G. Q. Li, and D. K. Liu, "Exact solutions for longitudinal vibration of rods coupled by translational springs," International Journal of Mechanical Sciences, vol. 42, no. 6, pp. 1135-1152, 2000.

[28] T. Triantafyllidis, "Dynamic stiffness of rigid rectangular foundations on the half-space," Earthquake Engineering \& Structural Dynamics, vol. 14, no. 3, pp. 391-411, 1986. 
[29] J. P. Wolf and D. R. Somaini, "Approximate dynamic model of embedded foundation in time domain," Earthquake Engineering \& Structural Dynamics, vol. 14, no. 5, pp. 683-703, 1986.

[30] D. Huang and T.-T. Zhu, "Experimental and numerical study on the strength and hybrid fracture of sandstone under tension-shear stress," Engineering Fracture Mechanics, vol. 200, pp. 387-400, 2018. 